\title{
Claudius Amyand's Hernia a Rare Cause of Acute Scrotum a Case Report
}

\author{
Coulibaly $\mathrm{MB}^{1 *}$, Diouf $\mathrm{C}^{2}$, Coulibaly $\mathrm{Y}^{3}$, Diaby $\mathrm{S}^{4}$, Coulibaly $\mathrm{OM}^{3}$, Amadou $\mathrm{I}^{3}$, Kamate $\mathrm{B}^{3}$, Malle $\mathrm{K}^{4}$, Kone $\mathrm{J}^{1}$, Coulibaly
} $\mathrm{Y}^{4}$, Kone $\mathrm{I}^{5}$, Traore $\mathrm{M}^{5}$, Kone $\mathrm{D}^{1}$, Dembele $\mathrm{B}^{6}$, Dao $\mathrm{M}^{3}$, Keita $\mathrm{M}^{3}$

${ }^{1}$ Department of Surgery and Specialties, Anesthesia in referral health centre " de la commune V " of Bamako, Mali

${ }^{2}$ Department of Surgery and Specialties Training and Research Unit in Health Sciences, Assane Seck University of Ziguinchor, Senegal

${ }^{3}$ Service Paediatric Surgeon, CHU Gabriel Toure, Bamako, Mali

${ }^{4}$ Service Paediatric Surgeon, Mopti Regional Hospital Center, Mali

5Pediatrics unit in referral health centre " de la commune V" of Bamako, Mali

${ }^{6}$ Bamako Dermatological Hospital, Bamako, Mali

DOI: $10.36347 / \mathrm{sajb} .2020 . \mathrm{v} 08 \mathrm{i01.003}$

| Received: 27.12.2019| Accepted: 04.01.2020 | Published: 28.01.2020

*Corresponding author: Mamadou Bernard Coulibaly

Abstract

Case Report

The incarceration of the vermicular appendage through the hernial sac is commonly referred to as Claudius Amyand's hernia. It is a rare and exceptional pathology in children. We report the case of a 7-month-old boy with an acute swelling scrotum due to a strangulated inguino scrotal hernia who has been admitted to paediatric emergencies. The management consisted in a conditioning and a preoperative assessment. An exploration revealed in the hernial sac an appendix of normal appearance. An appendectomy and a closure of the hernial sac were done. The evolution was uneventful.

Keywords: Amyand's hernia, intra hernial appendage, Infant.

Copyright @ 2020: This is an open-access article distributed under the terms of the Creative Commons Attribution license which permits unrestricted use, distribution, and reproduction in any medium for non-commercial use (NonCommercial, or CC-BY-NC) provided the original author and source are credited

\section{INTRODUCTION}

Claudius Amyand's hernia is characterized by the presence of the vermicular appendix in an inguinal or inguinoscrotal hernia, whether the latter is inflammatory or not [1-4]. Claudius Amyand, surgeon of King George II, was the first to describe it in 1735. Since then, the presence of the appendix in an inguinal hernia has been described as "Amyand's hernia" and remains rare [1, 2]. We present a case of Amyand's hernia discovered during a surgical cure for a strangulated right inguinal hernia in a seven-month-old boy. An appendectomy with resection closing of the hernial sac was done. The operative outcomes were simple.

\section{OBSERVATION}

A seven-month-old boy has been received in the paediatric emergency service for inguino-scrotal tumour appeared 3 hours before admission. At the medical examination the infant was conscious, he had $37.3^{\circ}$ of corporal temperature, and he was haemodynamicaly and respiratory stable. Physical examination revealed an acute swelling and irreducible scrotum (Figure-1).

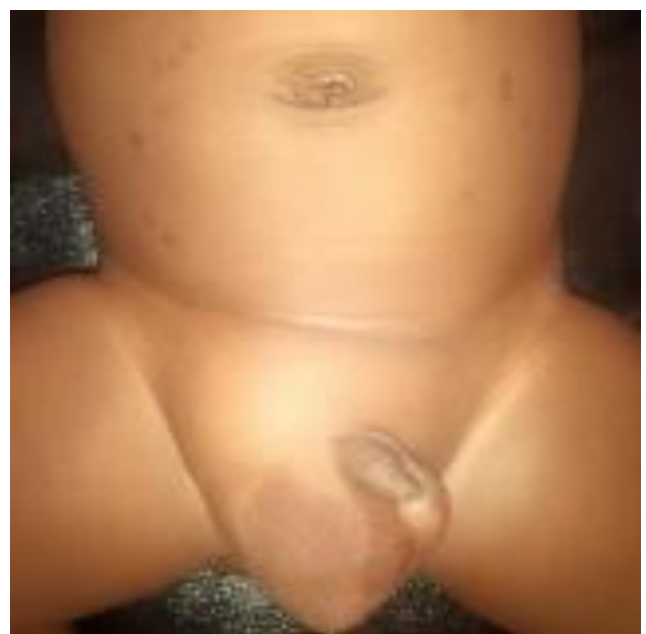

Fig-1: Non reducible acute right inguinal and scrotal swelling at admission

The rest of the clinical examination was normal and the diagnosis of strangulated right inguino-scrotal hernia was made. The preoperative biological assessment was normal.

The inguinal surgical approach revealed a macroscopically normal caecum and appendix in the 
hernial sac. Reduction of the herniated colon was performed associated with appendectomy and closure of the hernial sac (Figure-2). The postoperative course was simple.

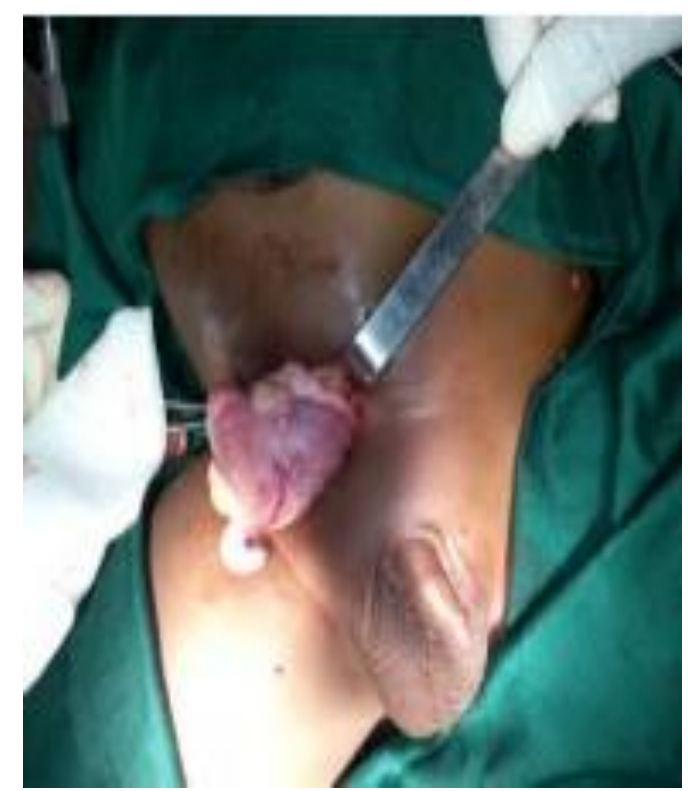

Fig-2: Vermicular appendix and caecum contained in the hernial sac

\section{DISCUSSION}

The hernia of "Claudius Amyand" is a rare entity in children and very few studies have been done on it [1,2]. The incidence of this hernia with a normal appendix in the inguinal hernial sac is about $1 \%$ and the appendiceal complications associated represent $0.1 \%$ [3]. Amyand's hernia can be found at all ages [1, 2, 4]. In our context it was a seven-month-old infant. The clinical presentation is polymorphic ranging from isolated inguino-scrotal swelling to a strangulated hernia with or without occlusive syndrome [2, 4, 5, 7]. Amyand's hernia is rarely diagnosed preoperatively [2, 6, 7]. In our context it was fortuitous discovery. We performed a standard preoperative assessment that was normal, however, a plain thoracoabdominal X-ray or inguinoscrotal ultrasound can be performed when there is an associated complication [2, 3, 4]. A location on the left during a defect of rotation of the primitive intestinal loop can be found [7]. The management of this pathology usually consists of an appendectomy with reintegration of the herniated colon and resection then closure of the hernial sac [1-7]. The postoperative outcome in the absence of complications are similar to those pathologies of the peritoneal-vaginal canal and of appendectomy.

\section{CONCLUSION}

Claudius Amyand's hernia is rare in children. His diagnosis is usually fortuitous. It represents a potentially serious pathology in the event of complications essentially related to the delayed diagnosis. The surgery consists at appendectomy with resection and closing of the hernial sac.

Conflict of Interest: Authors do not declare any conflict of interest in relation to this article

\section{REFERENCES}

1. Pellegrino JM, Feldman SD. Case report: acute appendicitis in an inguinal hernia. New Jersey medicine: the journal of the Medical Society of New Jersey. 1992 Mar;89(3):225-6.

2. Ngom G, Amadou I, Ibrahima KA, Mubake A, Ndour O, Ndoye M. Amyand's hernia with perforated appendix in a neonate. Case Reports. 2010 Jan 1;2010:bcr0320102847.

3. Logan MT, Nottingham JM. Amyand's hernia: a case report of an incarcerated and perforated appendix within an inguinal hernia and review of the literature. The American Surgeon. 2001 Jul 1;67(7):628-9.

4. Cherrabi H, Idrissa S, Abouljaoud H, Diallo AH, Atarraf K, Madi AE, Khattala K, Bouabdallah Y. Acute appendicitis due to Claudius Amyand's hernia in a newborn with intestinal obstruction. The Pan African medical journal. 2018;29:96.

5. Sengul I, Sengul D, Aribas D. An elective detection of an Amyand's hernia with an adhesive caecum to the sac: Report of a rare case. North American journal of medical sciences. 2011 Aug;3(8):391-393.

6. Luchs JS, Halpern D, Katz DS. Amyand's hernia: prospective CT diagnosis. Journal of computer assisted tomography. 2000 Nov 1;24(6):884-6.

7. Gupta S, Sharma R, Kaushik R. Left-sided Amyand's hernia. Singapore medical journal. 2005 Aug;46(8):424. 